\title{
Trends in Attitudes Towards Orofacial Cleft by Pregnant Women and Future Need for Cleft Care
}

\author{
Kadagad P1, Pinto P²
}

\begin{abstract}
AIM: To investigate the attitude of pregnant women towards prenatal ultrasound diagnosis of orofacial cleft and its impact on the future needs of cleft treatment.

METHODS: 100 subjects consulting the department of obstetrics and gynecology of KLE PK Hospital and Medical research centre were interviewed using a questionnaire.

RESULTS: Only 3 patients out of 100 patients chose the option of medical termination of pregnancy over continuation of pregnancy on prenatal ultrasound diagnosis of cleft.

CONCLUSION: Majority of pregnant women chose to continue pregnancy on prenatal ultrasound diagnosis of cleft; hence the implication to scale up the provision of future cleft therapy.
\end{abstract}

Keywords: Pregnant women, Prenatal, Orofacial cleft

${ }^{1}$ Reader

Department of Oral and Maxillofacial Surgery,

KLEVK Institute of dental sciences

KLE University, Belgaum, Karnataka, India

2 Professor

Department of Oral and Maxillofacial Surgery,

KLEVK Institute of dental sciences

KLE University, Belgaum, Karnataka, India

\section{Contact Autbor}

Dr Poornima Kadagad poornimakadagad@gmail.com

J Oral Health Comm Dent 2013;7(3)134-136

\section{INTRODUCTION}

he incidence of cleft lip and palate in India is 1 in every 700 live births leading to 27,000 to 33,000 new cleft patients every year (1). The estimated cleft population in India remains more than an average of 30,000 because of backlog of unoperated cleft patients which have been accumulating due to lack of awareness about treatment and access to healthcare facilities. Deficiency of birth defects registry makes it difficult to know the actual number of cleft patients in the country (2). Intervention by NGOs like smile train since 2000 has led to setting up of local centers which actually work full time and manage cleft patients in a comprehensive manner in comparison to surgical missionary teams which used to visit developing countries like India to treat cleft patients at intervals. Advances in ultrasound technology, its availability across the country and prenatal diagnosis of cleft has made alternate treatment choices available to the population with respect to reproduction (3). The attitude of the population towards prenatal diagnosis of cleft using transvaginal sonography and its effect on the rate of incidence of cleft needs to be assessed in the Indian context. This will also determine the future treatment needs for cleft lip and palate patients.

\section{MATERIALS AND METHODS}

KLE Prabhakar Kore Charitable hospital is an 800 bedded hospital and the department of obstetrics and gynecology caters to the population of Belgaum city and the villages around. 100 patients reporting to the department of obstetrics and gynecology were interviewed using a structured closed ended questionnaire which included the demographic data of the subjects. Preoperative and postoperative pictures of unilateral and bilateral cleft lip and cleft palate patients were shown to patients, followed by a hypothetical question, asking what would be their decision if prenatal ultrasound diagnosed a cleft fetus.

\section{RESULTS}

Out of 100 patients interviewed, only 3 
patients chose the option of terminating pregnancy on ultrasound diagnosis of

cleft. 94 patients opted to continue with pregnancy and 3 of them refused to an-

\begin{tabular}{|c|c|c|}
\hline Characteristic & & $N=100$ \\
\hline \multicolumn{3}{|l|}{ Respondents' age } \\
\hline $18-20$ & & 26 \\
\hline $21-25$ & & 56 \\
\hline $26-30$ & & 15 \\
\hline $31-35$ & & 5 \\
\hline \multirow[t]{4}{*}{ Education } & $<7^{\text {th }}$ grade & 7 \\
\hline & $<10^{\text {th }}$ grade & 13 \\
\hline & $10^{\text {th }}$ grade & 41 \\
\hline & 11 th $-12^{\text {th }}$ & \\
\hline \multicolumn{3}{|l|}{ Grade } \\
\hline & Graduate & 9 \\
\hline & Illiterate & 5 \\
\hline \multicolumn{3}{|l|}{ Occupation } \\
\hline & House wife & 92 \\
\hline & Employed & 8 \\
\hline \multirow[t]{3}{*}{ Spouse occupation } & Agriculture & 21 \\
\hline & Business/self employed & 75 \\
\hline & Professional & 4 \\
\hline \multirow[t]{2}{*}{ Religion } & Hindu & 95 \\
\hline & Muslims & 5 \\
\hline \multirow[t]{2}{*}{ Type of family } & Joint family & 85 \\
\hline & Nuclear family & 15 \\
\hline \multicolumn{3}{|l|}{ Area of residence } \\
\hline Village & & 60 \\
\hline Town & & 40 \\
\hline
\end{tabular}

Table 2: Responses of the subjects on choice of treatment after hypothetical prenatal diagnosis of cleft fetus.

\begin{tabular}{|lc|}
\hline $\begin{array}{l}\text { Question } \\
\text { Choice of treatment if prenatal ultrasonography revealed }\end{array}$ \\
\hline a fetus with cleft & 94 \\
\hline Continue pregnancy & 3 \\
\hline Medical termination of pregnancy & 3 \\
\hline Refused to answer & \\
\hline & 1 \\
\hline Decision maker in the family & 37 \\
\hline Mother & 34 \\
\hline Father & 20 \\
\hline Elders at home & 5 \\
\hline Combined (parents + elders) & 1 \\
\hline Mother and father & \\
\hline Refused to answer & \\
\hline
\end{tabular}

swer the question. $87 \%$ of them were post high school educated and $92 \%$ of them unemployed (housewives). $96 \%$ of their husbands were either farmers or self employed in small businesses with annual income of less than 1 lakh. $95 \%$ of them were Hindus and $5 \%$ Muslims and $85 \%$ of them lived in joint families (Table 1 and 2)

\section{DISCUSSION}

$94 \%$ of the subjects in our study chose the option of continuing pregnancy on hypothetical prenatal ultrasound diagnosis of cleft. The results of our study are congruent with a study by Dhavalbhakta and Hall (4) where they analyzed retrospectively 124 operated primary cleft repairs over 5 years. They found that $92 \%$ of them had not contemplated termination of pregnancy on diagnosis of cleft and only $1 \mathrm{pa}-$ tient had terminated her pregnancy on diagnosis of bilateral cleft lip and palate. Our study is different from the previous study in that the subjects had actual diagnosis of cleft fetus and in our study the responses were to a hypothetical situation of cleft diagnosis. A study by Diego F.Wyszynski, Claudia Perandones, Ricardo Bennum (5) interviewed parents of cleft children on prenatal diagnosis of cleft and choice of treatment; they found that only 6.4 of 165 patients opted to terminate pregnancy. The parents of cleft children who chose to continue pregnancy opined that non syndromic oral cleft is a non lethal birth defect.

Decision to terminate pregnancy on prenatal diagnosis of cleft ranges from 0 to $92 \%$ based on whether the cleft is associated with other malformations (6). Bronshtein M, Blumenfeld Z (7) and Blumenfeld Z, Blumenfeld I, Bronshtein M (8) have shown high rate of termination of pregnancy in their studies on prenatal ultrasound diagnosis of cleft. As these studies are conducted in developed countries it can be implied that access to healthcare and emphasis on cosmetically ideal child may be the attributing factors (9).

Another aspect of the cleft scenario in developing countries like India, the cleft back- 
$\log$ is being addressed (1) due to effort by international Non Governmental Organizations (NGO). This implies the need for resources to treat secondary cases and other comprehensive treatment for complete rehabilitation of such patients. As more cleft patients get accepted and integrated into the society the trend of incidence of cleft continues, and so does the demand for primary and secondary cleft services. Tendency towards avoiding medical termination of pregnancy on prenatal detection of cleft pregnancy as shown by the results of our study indicates that the rate of incidence of cleft may remain same if not increase, compelling the need of ample resources for management of cleft lip and palate patients.

\section{REFERENCES}

1. Peter Mossey, Julian Little. Addressing the challenges of cleft lip and palate research in India. Indian J Plast surg 2009;42(Supplement 1).

2. Mossey $\mathrm{Pa}$, Little J. Chapter 12, epidemiology of oral cleft: an international perspective In: Wyzsynki DF, editor Cleft lip and palate. From origin to treatment. Oxford University press. (Aug 2002) ISBN:0-19-513906-2.2002. p127-58

3. Surajit Bhattacharya. Winds of Change: Hope for Cleft lip and palate. Editorial. Indian J Plast Surg 2009;42(Supplement 1).

4. Dhavalbhakta A, Hall PN. The impact of antenatal diagnosis on the effectiveness and timing of counselling for cleft lip and palate. Br J Plast Surg 2000;53(4):298301.

5. Diego F. Wyszynski, Claudia Perandones, Ricardo Bennum. Attitudes toward reproduction by parents of children with nonsyndromic oral clefts in Argentina. Prenatal Diagnosis 2003;23(9)722-27.

6. Johnson N, Sandy JR. Prenatal diagnosis of cleft lip and palate. Cleft Palate Craniofac J 2003;40:186-89.

7. Bronshtein M, Blumenfeld Z. Early prenatal diagnosis of cleft lip and its potential impact on the number of babies with cleft lip. Br J Oral Maxillofac Surg 1996;34:486-87.

8. Blumenfeld Z, Blumenfeld I, Bronshtein M. The Early prenatal diagnosis of cleft lip and the decision making process. Cleft Palate Craniofacial J 1999;36:105-07.

9. Anna M Rozendaal, Antonius JM Luijsterburg, Edwin M Ongkosuwito, Esther de Vries, Christl Vermeij-Keers. Decreasing prevalence of oral cleft live births in the Netherlands, 1997-2006. Arch Dis Child Fetal Neonatal Ed doi:10.1136/adc.2010.193599. 